УДК 226.132; https://doi.org/10.37878/2708-0080/2021-6.05

\title{
КОНЦЕПТУАЛЬНЫЙ ПОДХОД К РАЗРАБОТКЕ МЕТОДОВ ПРОГНОЗИРОВАНИЯ ОПТИМАЛЬНОГО ВРЕМЕНИ РАБОТЫ ДОЛОТА
}

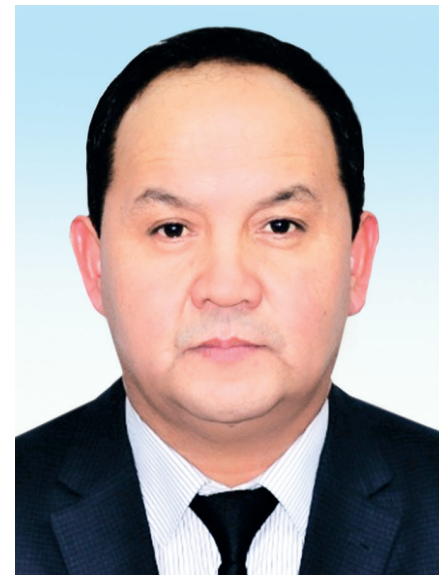

Б.Т. РATOB*1, доктор технических наук, профрессор, https://orcid.org/ 0000-00034707-3322

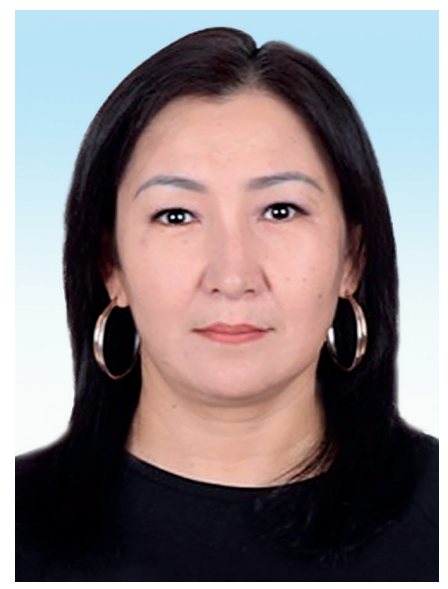

A.P. ТОГАШЕВА

кандидат технических наук, ассоц. профрессор, https://orcid.org/ 0000-0002$5615-2711$

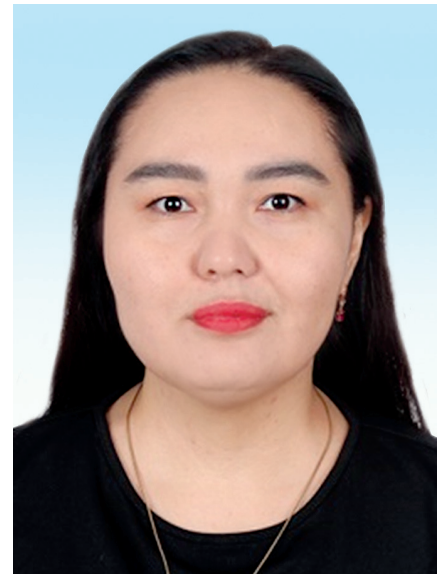

М.Д. САРБОПЕЕВА ${ }^{2}$, доктор $\mathrm{PhD}$, ассоц. профрессор, https://orcid.org/ 0000-00031721-119x

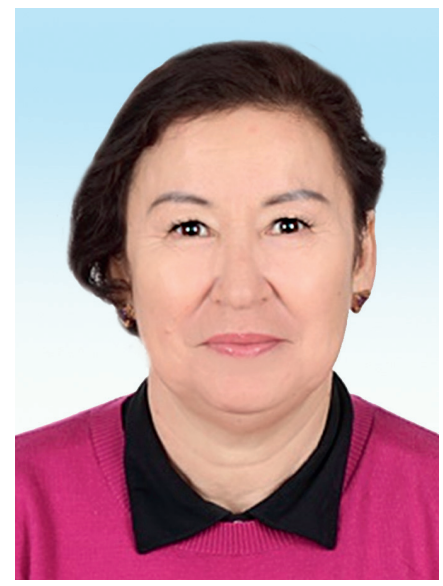

Р.У. БАЯМИРОВА², кандидат технических наук, ассоц. профрессор, https://orcid.org/ 0000-00031588-3144

\footnotetext{
* Адрес для переписки. E-mail: ratov69@mail.ru
} 
1'КАСПИЙСКИЙ ОБЩЕСТВЕННЫЙ УНИВЕРСИТЕТ, Республика Казахстан, 050000, г. Алматы, пр. Сейфуллина, 521

\author{
КАСПИЙСКИЙ ГОСУДАРСТВЕННЫЙ УНИВЕРСИТЕТ ТЕХНОЛОГИЙ \\ И ИНЖИНИРИНГА ИМ. Ш. ЕСЕНОВА, \\ Республика Казахстан,130000, г. Актау, 32-й м-н
}

В статье приводятся последовательность и результаты анализа геолого-технологической инфрормации о бурении скважин, показаны пути принятия концептуального решения по выбору наилучших типов долот и режимных параметров. При этом используется два критерия: рейсовая скорость и стоимость метра проходки с применением положений теории нечётких множеств.

Результаты выполненных исследований при наличии предварительных показателей работы долота, позволяющих строить в различной степени однотипные математические модели, принимаются как базовые с возможностью развития.

Однако при конкретных геологических условиях практическое применение этих моделей было затруднено вследствие специфических особенностей рассматриваемых условий, различного рода неопределенностей, неоднородности геологического разреза. Последнее обусловило необходимость расчленения геологических разрезов методами математической статистики на пачки одинаковыми категориями буримости горных пород.

КЛЮЧЕВЫЕ СЛОВА: долота, скважина, модель буримости, долото PDC, износ, сравнительная оценка, шарошечные долота, гудрон, поглощение.

\title{
ҚАШАУДЫҢ ОНТАЙЛЫ ЖҰМЫС УАҚЫТЫН БОЛЖАУ ӘДІСТЕРІН ӘЗІРЛЕУГЕ ТҰЖЫРЫМДАМАЛЫҚ КӨЗҚАРАС
}

Б.Т. РАТОВ ${ }^{\star 1}$, техника ғылымдарының докторы, професcop, https://orcid.org/0000-0003-4707-3322 М.Д. САРБОПЕЕВА², доктор PhD, ассоц. профресcop, https://orcid.org/ 0000-0003-1721-119x A.P. ТОГАШЕВА ${ }^{2}$, техника ғылымдарының кандидаты, ассоц. профреcсор, https://orcid.org/ 00000002-5615-2711

P.У. БАЯМИРОВА², техника ғылымдарының кандидаты, ассоц. профресcop, https://orcid.org/ 00000003-1588-3144

${ }^{1}$ КАСПИЙ ҚОҒАМДЫҚ УНИВЕРСИТЕТІ,

Қазақстан Республикасы, 050000, Алматы қ-сы, Сейфуллин д-ы, 521

${ }^{2}$ КАСПИЙ МЕМЛЕКЕТТІК ТЕХНОЛОГИЯЛАР

ЖӘНЕ ИНЖИНИРИНГ УНИВЕРСИТЕТІ Ш. ЕСЕНОВА,

Қазақстан Республикасы, 130000, Ақтау қ-сы, 32-ші шағын аудан

Мақалада ұңғымаларды бұрғылау туралы геологиялық және технологиялық ақпаратты талдаудың дәйектілігі мен нәтижелері, қашаудың ең жақсы түрлері мен режим параметрлерін таңдау туралы тұжырымдамалық шешім қабылдау жолдары көрсетілген. Бұл жағдайда екі критерий қолданылады: тұрақты жылдамдық және анық емес жиынтықтар теориясының ережелерін қолдана отырып, бір метр ұңғыманың құны.

Орындалған зерттеулердің нәтижелері әр түрлі дәрежеде бірдей математикалық модельдерді құруға мүмкіндік беретін қашаудың алдын-ала көрсеткіштері болған кезде даму мүмкіндізімен негізаі болып қабылданады.

Алайда, нақты геологиялық жағдайларда бұл модельдерді практикалық қолдану қарастырылған жағдайлардың нақты сипаттамаларына, әр түрлі белгісіздіктерге және геологиялық бөлімнің гетерогенділігіне байланысты қиын болды. Соңғысы геологиялық қималарды математикалық статистика әдістерімен тау жыныстарының бұрғылануының бірдей категорияларымен пакеттерге бөлуді қажет етmі.

ТYЙıн сөзДЕР: қашау, ұңғыма, бұрғылау моделі, PDC қашауы, тозу, салыстырмалы бағалау, шароштық қашау, гудрон, сіңіру. 


\title{
CONCEPTUAL APPROACH TO DEVELOPMENT OF METHODS FOR FORECASTING OPTIMAL BIT OPERATIONAL TIME
}

B. RATOV*1, Doctor of Technical Sciences, Professor, https://orcid.org/0000-0003-4707-3322

M. SARBOPEEVA ${ }^{2}$, PhD. associate professor, https://orcid.org/ 0000-0003-1721-119x

A. TOGASHEVA ${ }^{2}$, Candidate of Technical Sciences associate professor, https://orcid.org/ 00000002-5615-2711

R. BAYAMIROVA², Candidate of Technical Sciences associate professor, https://orcid.org/ 00000003-1588-3144

\author{
${ }^{1}$ CASPIAN PUBLIC UNIVERSITY, \\ 521, Seifullin Ave, 050000, Almaty, Republic of Kazakhstan \\ ${ }^{2}$ YESSENOV CASPIAN STATE UNIVERSITY \\ OF TECHNOLOGIES AND ENGINEERING, \\ 32nd microdistrict, 130000, Aktau, Republic of Kazakhstan
}

The article provides the sequence and results of the analysis of geological and technological information about well drilling, shows the ways of making a conceptual decision on the choice of the best types of bits and operating parameters. In this case, two criteria are used: the cruising speed and the cost per meter of penetration using the provisions of the theory of fuzzy sets.

The results of the studies carried out in the presence of preliminary indicators of the bit operation, which allow building the same type of mathematical models to varying degrees, are taken as basic with the possibility of development.

However, under specific geological conditions, the practical application of these models was difficult due to the specific features of the conditions under consideration, various kinds of uncertainties, and heterogeneity of the geological section. The latter made it necessary to subdivide geological sections by the methods of mathematical statistics into units with the same categories of rock drillability.

KEY WORDS: bits, well, drillability model, PDC bit, wear, comparative evaluation, roller cone bits, tar, lost circulation.

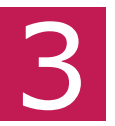

адача выбора долот, параметров режима и эффективного управления процессом бурения скважин была актуальна во все времена. Сложность этого процесса обусловлена необходимостью проведения глубокого анализа различных факторов, обоснования граничных критериев и методов построения структуры моделей. К настоящему времени накопилось достаточное количество результатов исследований, посвященных изучению механизма взаимодействия долота с породой, предложены методы для изучения физико-механических свойств горных пород, механизма их разрушения и влияния природных, технических технологических факторов на технико-экономические показатели работы долот. Известные методы поиска оптимальных параметров режима бурения согласно рекомендациям ряда специалистов [1-3] можно разделить на три основные группы:

- экспертные методы, на основе проведения физического моделирования и аналитических исследований;

- методы, основанные на моделировании единичного акта воздействия элемента вооружения долота на породу (требуют наличия большого объема кернового материала, что для проведения предусмотренного эксперимента полностью обеспечить практически невозможно). 
- методы, относящиеся к третьей группе, предполагают выполнения комплекса полевых экспериментальных работ на основе бурения в заданных интервалах глубин скважин, выбранными новыми долотами на заданных режимах бурения с камеральной обработкой полевых материалов (требуют проведения дорогостоящих и трудоемких наблюдений в промысловых условиях).

Как показывает анализ выполненных исследований, по результатам промысловых экспериментов невозможно описать процесс с помощью единых закономерностей. В то же время использование долот с высокой ударной прочностью позволило сократить время бурения на 8-5 дней и установить рекорды по максимальной механической скорости проходки и минимальному количеству рейсов долота. [3]

Для успешного применения таких методик необходима соответствующая модель, построенная по данным текущего контроля процесса бурения. Наиболее широко распространены стендовые исследования. Как известно, преимуществом стендовых экспериментов по изучению работы долот является возможность управления факторами, однако все же построенные по данным результатам модели нуждаются в идентификации к реальным условиям [4-9]. Это связано с появлением в реальных условиях различных неучтенных факторов, а также различного рода неопределённостей. Учитывая появление и широкое распространение систем геолого-технологического контроля, позволяющих получать относительно точную информацию, в качестве исходных данных для статистического анализа представляется возможным использовать фактические результаты отработок долот в реальных условиях.

Постановка задачи и результаты исследований. В настоящей статье в качестве примера приводятся результаты анализа данных о бурении скважины на одном из месторождений. По данным бурения были оценены литолого-фациальные особенности, фильтрационно-емкостные и физико-механические свойства горных пород по разрезу скважин. Исходным массивом данных, полученных в составе технологических исследований, являются технологические показатели бурения, а именно: осевая нагрузка на долото, частота вращения породо-разрушающего инструмента, плотность буровой промывочной жидкости, механическая скорость бурения, диаметр долота.

С помощью соответствующей программы по этим данным на основе методов d-экспоненты и сигма-каротажа были произведены расчеты пористости, проницаемости, градиента порового давления по $\mathrm{d}_{0}$-экспоненте, градиента порового давления по сигма-каротажу, коэффициента Пуассона, твердости пород, градиента давления гидроразрыва, абразивности, интенсивности затухания механической скорости. Выполнен анализ также технико-экономических показателей бурения скважин.

При обработке данных графиков, характеризующих изменение технико-экономических показателей, наблюдается большой разброс точек и высокие их амплитуды, в связи с чем нами был применен один из методов сглаживания динамических рядов метод скользящей средней (иногда его называют «методом скользящего окна») [2]. Метод скользящей средней основан на свойстве средней погашать случайные отклонения от общей закономерности. Расчет скользящей средней осуществляется по средней арифметической простой из заданного числа уровней ряда, с отбрасыванием, при вычислении каждой новой средней, предыдущего уровня и присоединением 
следующего. Сглаживание методом простой скользящей средней заключается в том, что вычисляется средний уровень из 3,5,7 и т.д. уровней. В результате, расчет средней, как бы, скользит от начала ряда динамики к его концу. При нечетном шаге каждая вычисленная скользящая средняя соответствует реальному интервалу (моменту) времени, находящемуся в середине шага (интервала), а число сглаженных уровней, меньше первоначального числа уровней на величину шага скользящей средней, уменьшенного на единицу. Например, формула для расчета 3 - шаговой скользящей средней будет выглядеть следующим образом:

$$
y_{1}=\frac{\sum_{i=1}^{3} y_{i}}{3} ; y_{2}=\frac{\sum_{i=2}^{4} y_{i}}{3} ; y_{3}=\frac{\sum_{i=3}^{5} y_{i}}{3}
$$

где: $\mathrm{i}=1, \mathrm{i}=2, \mathrm{i}=3,-$ прогнозный период; $\mathrm{i}$ - период, предшествующий прогнозному периоду; у1, у2, уз, - прогнозируемый показатель.

Если шаг скользящей средней выражен четным числом, то полученные скользящие средние центрируют. Операция центрирования заключается в повторном скольжении с шагом, равным двум. Число уровней сглаженного ряда будет меньше на величину шага скользящей средней. Определение интервала сглаживания (число входящих в него уровней) зависит: если необходимо сгладить беспорядочные колебания, то интервал сглаживания берут большим (до 5-7 уровней). Если же есть необходимость сохранить периодически повторяющиеся колебания, то интервал сглаживания уменьшают до 3 уровней. Согласно данному методу выбирается некоторое количество точек, которое при построении зависимостей можно изменить или уточнить. В рассматриваемом случае оно выбрано равным 3. Вначале усредняются по абсциссе и ординате первые три точки, затем, начиная со второй, следующие три и т.д. В результате получается осредненный ряд. По этим данным строятся зависимости проходки на долото, механической скорости и стоимости метра проходки от глубины. При этом, заметно снижение амплитуды точек. В то же время тенденция обработанных методом трехточечной скользящей средней, до интервалов глубин 3800-4100м (На примере месторождения Кюровдаг (Азербайджан), в целом наблюдаются незначительные изменения технико-экономических показателей отработки долот. На отмеченном интервале наблюдается всплеск, то есть, резкое увеличение стоимости метра проходки, что может быть объяснено отбором на данном интервале глубин керна, и/или увеличением твердости горных пород, приведшим к снижению скорости бурения и, соответственно, увеличению стоимости бурения в целом. [3].

Выбор долот и режимных параметров для конкретных условий бурения является важнейшим фактором оптимизации и снижения стоимости буровых работ. Исходя из этого, для облегчения процесса выбора долот, составлен классификатор. Тем не менее, вопросы выбора долот и режимных параметров требуют постоянного изучения закономерностей процесса разрушения горных пород, сравнительного анализа показателей работы долот в различных условиях их отработки на основе классификации горных пород по их свойствам на однородные группы. 
Как отмечается в литературе, сравнение долот фирм Hughes Christensen с российскими долотами показало, что последние уступают по проходке на $27 \%$, стойкости на $24 \%$ и по механической скорости на $4 \%$. Закономерностей разрушения горных пород этими типами долот в сравнении с долотами, которые относительно чаще встречаются при бурении скважин в различных условиях, на сегодняшний день выполнено относительно немного. Выполненный в рассматриваемых скважинах комплекс геолого-технологических и геофизических исследований, позволяет иметь полное представление об условиях, технологии и показателях процесса бурения. Исходя из этого, нами проводился анализ на данных, полученных по результатам геолого-технологических исследований в скважине с целью оптимизации режимных параметров бурения.

В результате такого анализа, на наш взгляд, необходимо построение моделей, позволяющих прогнозировать показатели работы долот. Следует отметить, что рассматриваемые долота отличаются высокой производительностью и долговечностью.

В комплекс работ по прогнозированию показателей бурения и принятию оптимальных решений входят оценка показателей свойств горных пород и классификация геологического разреза по этим характеристикам на однородные пачки. Выполненный в рассматриваемых скважинах комплекс геолого-технологических и геофизических исследований позволяет иметь полное представление об условиях, технологии и показателях процесса бурения.

Для принятия решений необходимо сформировать вначале базу данных.

Таким образом, исходная информация может быть различной:

- результаты по ранее пробуренным на данной площади (месторождении) или аналогичных площадях (месторождениях) скважинам;

- результаты, поступающие в процессе бурения, которые имеют важное значение при недостаточной информации о бурении скважин или ее отсутствии.

От характера исходной информации, полученной тем или иным путем, зависит и подход, осуществляемый к принятию решений. В связи с этим нами расмотрены вопросы принятия решений в том и другом случае. Схематически общий алгоритм принятия решений приведён на блок-схеме, показанной на рисунке 1.

Из рисунка 1 видны пути анализа и принятия решений в случае использования информации по ранее пробуренным скважинам, а также по результатам геолого-технологических исследований в процессе бурения скважин. Согласно данному алгоритму при постановке задачи необходимо установить основные переменные величины, определить соотношение между ними, установить характер изучаемых условий, и, таким образом, подойти к построению модели. Процессы построения модели и сбора, обработки данных, то есть получения информации, зависят от характера информации. Если по ранее пробуренным скважинам имеется предварительная информация, то расчёты проводятся согласно блокам, расположенным на левой ветви схемы, если таких данных нет или они имеются в недостаточном объёме, то расчёты проводятся по данным геолого-технологических исследований в процессе бурения по мере их поступления. Согласно данному алгоритму процесс принятия решений реализуется в зависимости от характера исходной информации и в связи с этим на схеме показана последовательность расчётов для того и другого 


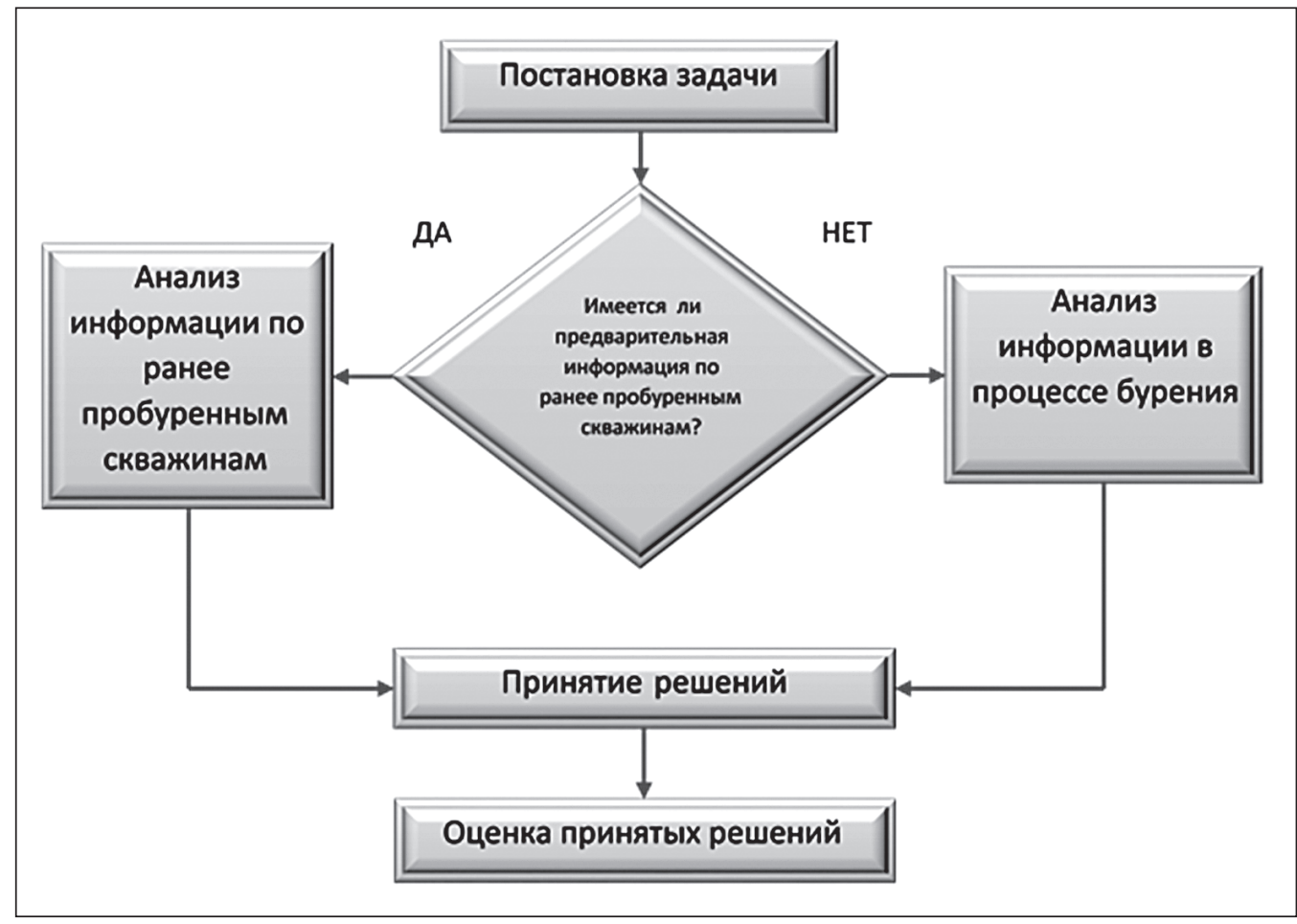

Рисунок 1 - Блок-схема принятия решений при бурении скважин в зависимости от характера исходной информации

случая. Все рассматриваемые при этом факторы, определяющие процесс бурения скважин, можно разделить на три группы. Об этом в той или иной степени отмечается в работах различных исследователей [4-7].

Процессы построения модели и сбора, обработки данных, то есть получения информации, зависят от характера информации. Если по ранее пробуренным скважинам имеется предварительная информация, то расчёты проводятся согласно блокам, расположенным на левой ветви схемы, если таких данных нет или они имеются в недостаточном объёме, то расчеты проводятся по данным геолого-технологических исследований в процессе бурения по мере их поступления.

Согласно приведенным условиям, был выполнен анализ, для чего разработана и реализована на конкретных примерах соответствующая программа. В качестве исходных используются данные бурения скважин, сгруппированные для однородной группы пород.

В результате статистического анализа путем соответствующих преобразований были построены линейные модели, для чего переменные представлены в логарифмах и преобразованы в мультипликативный вид. При этом по данным бурения скважин долотами Российского производства и РDC на месторождениях Кокмай, Карамандыбас, Аккудык, - (Казахстан), Кюровдаг (Азербайджан), Илетская (Россия) получены зависимости, параметры которых в процессе обработки уточнялись методом случайного поиска [1]. 
Получены также уравнения для соответствующих типов долот в данной породе, выражающие зависимость времени бурения от режимных параметров [2].

С целью проведения вариантных расчетов задавались границы изменения значения режимных параметров и их шаги. Для всех этих вариантов проводились расчеты рейсовой скорости и стоимости 1 м проходки. Наилучшие по прогнозам режимные параметры определялись с помощью отмеченных двух критериев с применением теории нечетких множеств. Согласно этому множество решений представляет собой пересечение множеств целей (добиться наибольшей рейсовой скорости) и ограничений (при наименьшей стоимости 1 м проходки). Для этого выбирался вид функции принадлежности множеств цели и ограничения. Для всех расчетных вариантов (при различных сочетаниях режимных параметров) рассчитывались функции принадлежности цели и ограничения.

\section{Выводы}

Обобщен опыт и систематизированы результаты исследований по конструкциям буровых долот, а также взаимодействия породоразрушающего инструмента с горными породами на забое скважин.

На основе результатов исследований полученных материалов с использованием математического описания была выполнена концептуальная разработка методов и средств оперативного определения физико-механических свойств и абразивности горных пород.

По предварительной оценке, предлагаемые методы позволят оценивать свойства горных пород по кернам, шламу, с помощью получаемых результатов петрографических (литолого-фациальных) исследований геолого-петрографических и направленных технологических исследований.

Такой подход позволит решить задачу выбора оптимальных типов долот и режимных параметров, как на стадии проектирования бурения скважин, так и при необходимости принятия оперативных решений непосредственно в процессе бурения.

\section{ЛИТЕРАТУРА}

1 Растригин Л.А. Адаптация сложных систем. - Рига: Зинатне, 1981. - 375 с. [Rastrigin L.A. Adaptatsiya slozhnykh sistem. - Riga: Zinatne, 1981. - 375 s.].

2 Сарбопеева М.Д. Анализ технико-экономических показателей бурения скважин // Управление качеством нефтегазового комплекса. - 2013. - №3. - С. 11-13. [Sarbopeeva M.D. Analiz tekhniko-ekonomicheskikh pokazateley bureniya skvazhin // Upravleniye kachestvom neftegazovogo kompleksa. - 2013. - №3. - S.11-13].

3 Эфендиев Г.М., Сарбопеева М.Д., Кызылгулов В.К. Выбор оптимальных параметров бурения // Нефрть и газ. - 2012. - №3. - C. 41. [Efendiyev G.M., Sarbopeeva M.D., Kyzylgulov V.K. Vybor optimal'nykh parametrov bureniya // Neft' i gaz. - 2012. - №3. - S. 41.].

4 Федоров Б. В., Ратов Б. Т. и др. Моделирование процесса бурения скважин долотами PDC на нефтегазовом месторождении Узень / Материалы I Международной научно-практической конференции «Булатовские чтения», Том.3, Бурение нефртяных и газовых скважин. Краснодар, 2017. - С. 267-272 [Fedorov B. V., Ratov B. T. i dr. Modelirovaniye protsessa bureniya skvazhin dolotami RDS na neftegazovom mestorozhdenii Uzen' / Materialy I Mezhdunarodnoy nauchno-prakticheskoy konferentsii «Bulatovskiye chteniya». Krasnodar, 2017. - S. 267-272]. 
5 Fedorov B., Ratov B., Sharauova A. Development of the model of petroleum well boreability with PDC bore bits for Uzen oil field (the Republic of Kazakhstan) // Eastern-European Journal of Enterprise Technologies. - 2017. - N 3. - P. 16-22. DOI: 10.15587/17294061.2017.99032

6 Ratov B. T., Fedorov B. V., Sabirov B. F., Korgasbekov D. R. Research parameters of an ejector knot of device for coring from deep well / News of the national academy of sciences of the Republic of Kazakhstan series of geology and technical sciences. -2017 . - Vol. 3. - N. 423. - P. 143 - 150.

7 Ратов Б.Т., Федоров Б.В., Хузина Л.Б., и др. Моделирование процесса углубления скважины долотами PDC // Нефть и газ. - 2017. - №4. - С. 77-85. [Ratov B.T., Fedorov B.V., Khuzina L.B., i dr. Modelirovaniye protsessa uglubleniya skvazhiny dolotami PDC // Neft' i gaz. - 2017. - №4. - S: 77-85.

8 Fedorov B., Ratov B., Sharauova A. Model of purification of PDC bolts for walking wells on oil-gas field name // News of the national academy of sciences of the Republic of Kazakhstan, Series of geology and technical sciences. - 2017. - Vol. 4. - N. 424. - P. 170 - 176.

9 Ратов Б.Т., Федоров Б.В. и др. Математическая модель процесса бурения долотами PDC / Сборник научных статей международной научно-практической конференции «Инновация-2017». Ташкент, 2017. - С. 228. [Ratov B.T., Fedorov B.V. i dr. Matematicheskaya model' protsessa bureniya dolotami PDC / Sbornik nauchnykh statey mezhdunarodnoi nauchno-prakticheskoi konferentsii «Innovatsiya-2017». - Tashkent, 2017. - S. 228. 